\title{
Prevalence and Factors Associated with Rotavirus Infection among Vaccinated Children Hospitalized for Acute Diarrhea in Mwanza City, Tanzania: A Cross Sectional Study
}

\author{
Dina Mahamba1,2, Adolfine Hokororo², Florentina Mashuda², Delfina R. Msanga', \\ Elice C. Bendera ${ }^{2}$, Elizabeth N. Kwiyolecha², Benson R. Kidenya3 ${ }^{3}$ Stephen E. Mshana4, \\ Mariam M. Mirambo 4
}

\begin{abstract}
${ }^{1}$ Department of Pediatrics \& Child Health, College of Health Sciences, University of Dodoma, Dodoma, Tanzania
${ }^{2}$ Department of Pediatrics and Child Health, Weill Bugando School of Medicine, Catholic University of Health and Allied Sciences, Mwanza, Tanzania

${ }^{3}$ Department of Biochemistry and Molecular Biology, Weill Bugando School of Medicine, Catholic University of Health and Allied Sciences, Mwanza, Tanzania

${ }^{4}$ Department of Microbiology and Immunology, Weill Bugando School of Medicine, Catholic University of Health and Allied Sciences, Mwanza, Tanzania

Email:mmmirambo@gmail.com
\end{abstract}

How to cite this paper: Mahamba, D. Hokororo, A., Mashuda, F., Msanga, D.R., Bendera, E.C., Kwiyolecha, E.N., Kidenya, B.R., Mshana, S.E. and Mirambo, M.M. (2020) Prevalence and Factors Associated with Rotavirus Infection among Vaccinated Children Hospitalized for Acute Diarrhea in Mwanza City, Tanzania: A Cross Sectional Study. Open Journal of Pediatrics, 10, 392-403.

https://doi.org/10.4236/ojped.2020.103040

Received: May 12, 2020

Accepted: July 12, 2020

Published: July 15, 2020

Copyright $\odot 2020$ by author(s) and Scientific Research Publishing Inc. This work is licensed under the Creative Commons Attribution International License (CC BY 4.0).

http://creativecommons.org/licenses/by/4.0/

\begin{abstract}
Introduction: Rotavirus infection is a leading cause of severe diarrhea culminating to dehydration among children under five years of age. Understanding trends and factors that could assist towards devising effective preventive strategies of Rotavirus infection beyond vaccination is crucial. Objectives: This study was done in an attempt to determine the prevalence and associated factors of Rotavirus infection among vaccinated children aged between 6 weeks and 24 months admitted with acute diarrhea Mwanza, Tanzania. Material and Methods: Across sectional study involving vaccinated children aged 6 weeks to 24 months was conducted in three selected hospitals from July 2017 to January 2018. Socio-demographic and other relevant clinical information were collected using a standardized data collection tool adopted from WHO Rotavirus surveillance tool. Rotavirus infection from the stool was detected using an enzyme immunoassay. Data were analyzed using STATA version 13. Results: A total of 301 vaccinated children with acute diarrhea with a median age of 12 [IQR: 8 - 17] months were enrolled. Nine (3.0\%) and $292(97.0 \%)$ had received one dose and two doses of Rotavirus
\end{abstract}


vaccine, respectively. The prevalence of Rotavirus infection was 74 (24.6\%) [95\% CI: 20.0 - 29.8]. Independent predictors of Rotavirus infection were: dry season (OR 6.9; 95\% CI: $2.9-16.0 ; \mathrm{p}<0.001), 3 \geq$ children indwelling in the same house (OR 2.1; 95\% CI: $1.1-4.2 ; \mathrm{p}=0.043$ ) and vomiting (OR 3.6; 95\% CI $1.1-12.6 ; \mathrm{p}=0.045)$. Children with Rotavirus infection had a significantly shorter hospital stay than those without Rotavirus infection (3 [2 - 4] days versus 3 [3 - 5] days; $p=0.0297$ ). Conclusions: The prevalence of Rotavirus infection has declined among vaccinated children in Mwanza, Tanzania with significant decrease in the hospital stay. Dry seasons, three or more children indwelling in the same house and vomiting were independent predictors of Rotavirus infection. There is a need to sustain the coverage of rotavirus vaccination in low-income countries in order to significantly reduce associated morbidity and mortality.

\section{Keywords}

Rotavirus, Vaccination, Diarrhea

\section{Introduction}

Diarrhea remains the second most common cause of death among children below five years of age worldwide [1]. Most of these deaths are due to severe dehydration, with the majority of deaths occurring in low and middle-income countries [1]. Globally, Rotavirus is the commonest cause of severe infantile diarrhea resulting in dehydration and prolonged hospital stay among children below five years of age [2] [3]. Development of a safe and effective Rotavirus vaccine has been a priority since Rotavirus disease cannot be eliminated through the improvement of water and sanitation [4]. The World Health Organization (WHO) authorized the Rotavirus vaccine for infants to be incorporated in all national immunization programme with strong emphasis in the countries where diarrhea disease cause more than $10 \%$ of death in children below five years of age [5].

In Tanzania, Rotavirus vaccine, a live attenuated human monovalent [G1P8] vaccine (Rotarix), was introduced in the National immunization program in January 2013. Despite the Rotavirus vaccine implementation, acute diarrhea with severe dehydration cases is still reported in this setting. The prevalence of Rotavirus infection prior and after vaccine implementation has been continuously studied, however, the trends such as seasonality, severity of disease, hospital stay and associated factors of Rotavirus infection have not been adequately studied among vaccinated children [6] [7] [8]. In a view of that, this study was done to determine the prevalence of Rotavirus infection and factors associated with acute diarrhea among vaccinated children aged 6 weeks to 2 years admitted in three hospitals in the city of Mwanza. The information from this study is important in assessing the trend of Rotavirus infection in this vaccination era. 


\section{Material and Methods}

\subsection{Study Design and Settings}

This was a hospital based cross sectional study involving 301 vaccinated children which was conducted from July 2017 to January 2018 in the city of Mwanza, Tanzania in three hospitals (Nyamagana District Hospital, Sekou Toure Regional Referral Hospital and Bugando Medical Centre).

\subsection{Sample Size, Sampling and Inclusion Criteria}

Sample size of the study was calculated using Kish Leslie formula [9] using the prevalence of $20.7 \%$ from Temu et al. [6]. The minimum sample size obtained was 250 children. All children who received at least one dose of Rotavirus vaccine as evidenced by RCH card aged 6 weeks to 24 months admitted for treatment of acute diarrhea within seven days duration irrespective of the other illnesses, were serially enrolled until the sample size was attained.

\subsection{Variables and Outcomes}

Socio-demographic data and relevant clinical information were collected using a structured pre-tested questionnaire adopted from WHO Rotavirus surveillance tool. Diarrhea was defined according to the WHO guidelines as passage of three or more loose, liquid or watery stools within 24 hours period [10]. Duration of illness, frequency of diarrhea, consistency of stool, history of fever, vomiting, history of Rotavirus vaccination were recorded followed by clinical examination to elicit hydration and nutritional status. All children were admitted and managed according to respective standard hospital guidelines. The duration of hospital stay for each child was noted.

\subsection{Laboratory Procedures}

All samples were collected and analyzed at the Bugando Medical Centre laboratory which is one of the WHO sentinel surveillance sites for Rotavirus gastroenteritis using enzyme-linked immunosorbent assay (The ProSpecT Rotavirus Microplate kit, Oxoid Ltd., UK) as per manufacturer's instructions.

\subsection{Data Analysis}

The data were analyzed using STATA software version 13. Continuous data were summarized using median with interquartile range (IQR) while categorical data were summarized using proportions. To determine the factors associated with Rotavirus infection univariable logistic regression followed by multivariable logistic regression models were performed. Factors that were statistically significant on univariable analysis were subjected to multivariable logistic regression model. Odd ratios with their respective $95 \%$ confidence interval were noted and a $\mathrm{p}$ value of less than 0.05 was considered statistically significant. To compare the median hospital stay after initiation of hospital management between vaccinated children with and without Rotavirus infection admitted for acute diarrhea, 
two-sample Wilcoxon rank-sum (Mann-Whitney) test was used.

\section{Results}

\subsection{Socio-Demographic Characteristics of Study Participants}

A total of 301 children with acute diarrhea admitted in three hospitals were recruited in the study with a median age of 12 [IQR: 8 - 17] months, of these 40 (13.3\%), 184 (61.1\%) and 77 (25.6\%) were from Nyamagana District Hospital, Sekou Toure Regional Referral Hospital and Bugando Medical Centre, respectively. Majority of children, 166/301 (55.2\%) were males and most of the children enrolled, 285/301 (94.7\%) were from urban areas (Table 1).

\subsection{Clinical Findings among Vaccinated Children with Acute Diarrhea}

The median duration of diarrhea was 3 [IQR: 2 - 5] days. The vaccine coverage for the first dose of Rotavirus vaccine was $100 \%$ whereas for the second dose it was $97.0 \%(292 / 301)$. There were $188 / 301$ (62.7\%) children with normal nutrition status. Of note, $34 / 301(11.3 \%)$ and $140 / 301$ (46.5\%) children had severe dehydration and some dehydration, respectively (Table 2 ).

\subsection{Prevalence of Rotavirus Infection among 301 Children with Acute Diarrhea}

Of the 301 children with acute diarrhea investigated, 74 (24.6\%) [95\% CI 20.0\% 29.8\%] had Rotavirus infection. The highest prevalence of Rotavirus infection was seen at Sekou Toure Regional Referral Hospital, 28.3\% (52/184) followed by Nyamagana District Hospital, 27.5\% (11/40) and Bugando Medical Centre, 14.3\% (11/77), Figure 1.

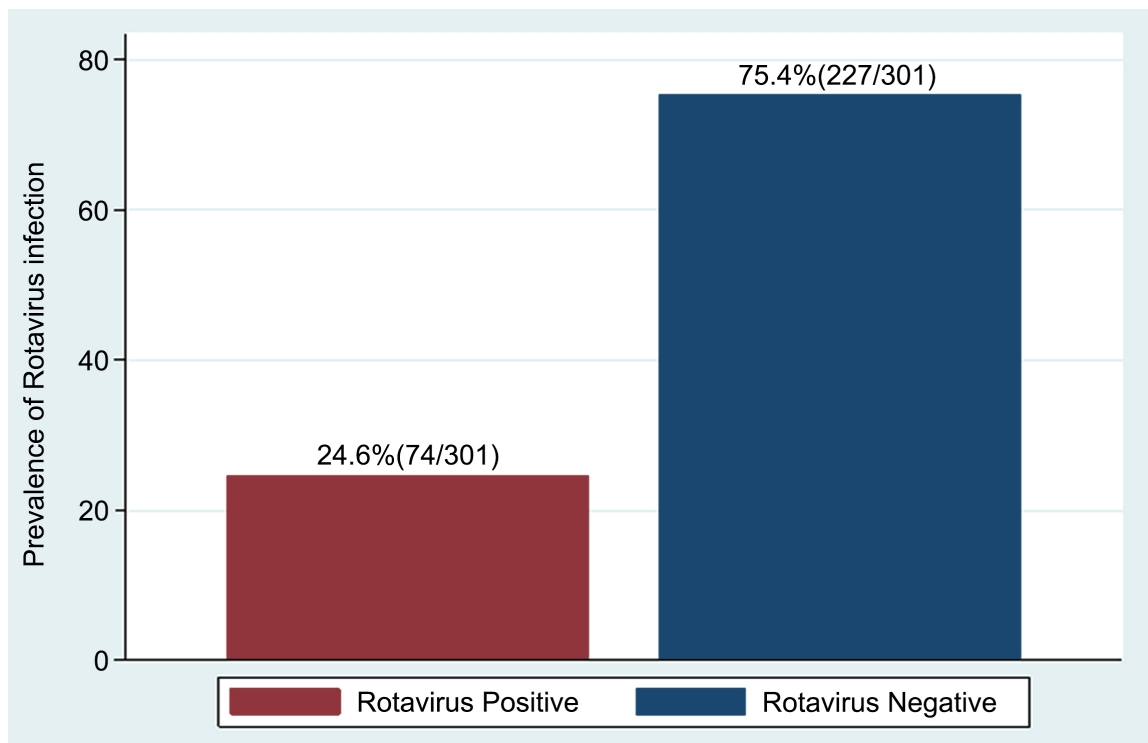

Figure 1. Distribution of Rotavirus infection among 301 vaccinated children with acute diarrhea. 
Table 1. Distribution of socio-demographic data of 301 children with acute diarrhea.

\begin{tabular}{|c|c|c|}
\hline Variable & Number (n) & Percent (\%) \\
\hline \multicolumn{3}{|l|}{ Hospital } \\
\hline Nyamagana & 40 & 13.3 \\
\hline Sekou-Toure & 184 & 61.1 \\
\hline Bugando & 77 & 25.6 \\
\hline \multicolumn{3}{|l|}{ Age of the child } \\
\hline $2-12$ months & 170 & 56.5 \\
\hline $13-24$ months & 131 & 43.5 \\
\hline \multicolumn{3}{|l|}{ Sex of child } \\
\hline Female & 135 & 44.8 \\
\hline Male & 166 & 55.2 \\
\hline \multicolumn{3}{|l|}{ Education of care giver } \\
\hline None & 34 & 11.3 \\
\hline Primary & 185 & 61.5 \\
\hline Secondary & 69 & 22.9 \\
\hline University & 13 & 4.3 \\
\hline \multicolumn{3}{|c|}{ Employment status of care giver } \\
\hline Employed & 32 & 10.6 \\
\hline Petty traders & 133 & 44.2 \\
\hline Non employed & 136 & 45.2 \\
\hline \multicolumn{3}{|c|}{ Marital status of care giver } \\
\hline Married & 256 & 85.1 \\
\hline Single or widowed & 45 & 14.9 \\
\hline \multicolumn{3}{|l|}{ Relationship } \\
\hline Mother & 279 & 92.7 \\
\hline Father & 14 & 4.7 \\
\hline Guardian & 8 & 2.7 \\
\hline \multicolumn{3}{|l|}{ Residence } \\
\hline Urban & 285 & 94.7 \\
\hline Rural & 16 & 5.3 \\
\hline \multicolumn{3}{|l|}{ Weaning period } \\
\hline$<6$ months & 184 & 61.1 \\
\hline$>6$ months & 117 & 38.9 \\
\hline \multicolumn{3}{|c|}{ Neighbour child with diarrhea } \\
\hline No & 232 & 77.1 \\
\hline Yes & 69 & 22.9 \\
\hline \multicolumn{3}{|l|}{ Source of drinking water } \\
\hline Lake & 8 & 2.7 \\
\hline Tap & 265 & 88.1 \\
\hline Well & 28 & 9.3 \\
\hline \multicolumn{3}{|l|}{ House type } \\
\hline Brick & 220 & 73.1 \\
\hline Mud/Thatch & 81 & 26.9 \\
\hline \multicolumn{3}{|c|}{ Number of underfive dwell in the house } \\
\hline 1 child & 142 & 47.2 \\
\hline 2 children & 92 & 30.6 \\
\hline 3 children & 40 & 13.3 \\
\hline$\geq 4$ children & 27 & 9.0 \\
\hline
\end{tabular}


Table 2. Clinical findings and vaccine status of 301 children with acute diarrhea.

\begin{tabular}{|c|c|c|}
\hline Variable & Number (n) & Percent (\%) \\
\hline \multicolumn{3}{|l|}{ Nutritional status } \\
\hline Normal & 188 & 62.7 \\
\hline Mild Malnutrition & 67 & 22.3 \\
\hline Moderate Malnutrition & 22 & 7.3 \\
\hline Severe Malnutrition & 23 & 7.7 \\
\hline \multicolumn{3}{|l|}{ Dehydration status } \\
\hline No dehydration & 127 & 42.2 \\
\hline Some dehydration & 140 & 46.5 \\
\hline Severe dehydration & 34 & 11.3 \\
\hline \multicolumn{3}{|l|}{ Duration of diarrhea } \\
\hline 1 - 3 days & 168 & 55.8 \\
\hline 4 - 7 days & 133 & 44.2 \\
\hline \multicolumn{3}{|l|}{ Consistency of diarrhea } \\
\hline Watery & 272 & 90.4 \\
\hline Watery + Mucoid & 29 & 9.6 \\
\hline \multicolumn{3}{|l|}{ Number of vaccine dose } \\
\hline 1 & 9 & 3.0 \\
\hline 2 & 292 & 97.0 \\
\hline
\end{tabular}

\subsection{Factors Associated with Rotavirus Infection}

On univariable logistic regression analysis, the factors associated with Rotavirus infection were: being admitted to Sekou Toure hospital (OR 2.4; 95\% CI 1.2 4.8; $\mathrm{p}=0.018$ ), dry season (OR 8.5; 95\% CI $3.8-19.4 ; \mathrm{p}<0.001$ ), three or more children indwelling in the same house (OR 2.4; 95\% CI $1.2-4.6 ; \mathrm{p}=0.009$ ), vomiting (OR 6.7; 95\% CI $2.0-22.1 ; \mathrm{p}=0.002$ ), formal education of caregiver (OR $3.7 ; 95 \%$ CI $1.1-12.6 ; \mathrm{p}=0.033)$. By multivariable logistic regression analysis the factors associated with Rotavirus infection were: dry season (OR 6.9; 95\% CI 2.9 - 16.0; $\mathrm{p}<0.001$ ), three or more children indwelling in the same house (OR 2.1; 95\% CI $1.1-4.2 ; \mathrm{p}=0.043)$ and vomiting (OR 3.6; 95\% CI $1.1-12.6 ; \mathrm{p}=0.045)$, Table 3.

\subsection{Hospital Stay of Vaccinated Children with Acute Diarrhea}

Children with Rotavirus infection had a significant shorter hospital stay than those without Rotavirus infection $(3[2-4]$ days versus 3 [3 - 5] days; $\mathrm{p}=$ 0.0297), Table 4 and Table 5. 
Table 3. Factors associated with Rotavirus infection among 301 children with acute diarrhea.

\begin{tabular}{|c|c|c|c|c|c|c|}
\hline \multirow{3}{*}{ Variables } & \multicolumn{2}{|c|}{ Rotavirus infection } & \multirow{2}{*}{\multicolumn{2}{|c|}{ Univariate }} & \multirow{2}{*}{\multicolumn{2}{|c|}{ Multivariate }} \\
\hline & \multirow{2}{*}{$\begin{array}{c}\text { Positive } \\
\text { n (\%) }\end{array}$} & \multirow{2}{*}{$\begin{array}{c}\text { Negative } \\
\mathrm{n}(\%)\end{array}$} & & & & \\
\hline & & & OR [95\% CI] & $\mathrm{p}$-value & OR $[95 \% \mathrm{CI}]$ & p-value \\
\hline \multicolumn{7}{|l|}{ Hospital } \\
\hline Bugando & $11(14.3)$ & $66(85.7)$ & 1.0 & & & \\
\hline Nyamagana & $11(27.5)$ & $29(72.5)$ & $2.3[0.9-5.8]$ & 0.087 & $1.6[0.6-4.7]$ & 0.347 \\
\hline Sekou-Toure & $52(28.3)$ & $132(71.7)$ & $2.4[1.2-4.8]$ & 0.018 & $2.1[0.9-4.7]$ & 0.067 \\
\hline \multicolumn{7}{|l|}{ Sex of the child } \\
\hline Female & $28(20.7)$ & $107(79.2)$ & 1.0 & & & \\
\hline Male & $46(27.7)$ & $120(72.4)$ & $1.5[0.9-2.5]$ & 0.164 & - & - \\
\hline \multicolumn{7}{|l|}{ Climate season } \\
\hline Rainy & $7(6.1)$ & 107 (93.9) & 1.0 & & & \\
\hline Dry & $67(35.8)$ & $120(64.2)$ & $8.5[3.8-19.4]$ & $<0.001$ & $6.9[2.9-16.0]$ & $<0.001$ \\
\hline \multicolumn{7}{|l|}{ Vomiting } \\
\hline No & $3(5.7)$ & $50(93.3)$ & 1.0 & & & \\
\hline Yes & $71(28.6)$ & $177(71.4)$ & $6.7[2.0-22.1]$ & 0.002 & $3.6[1.1-12.6]$ & 0.045 \\
\hline \multicolumn{7}{|l|}{ Dehydration } \\
\hline No & $29(22.8)$ & $98(77.2)$ & 1.0 & & & \\
\hline Yes & $45(25.9)$ & $129(74.1)$ & $1.2[0.7-2.0]$ & 0.547 & - & - \\
\hline \multicolumn{7}{|l|}{ Age of the child } \\
\hline $13-24$ months & $34(25.9)$ & $97(74.1)$ & 1.0 & & & \\
\hline $2-12$ months & $40(23.5)$ & $130(76.5)$ & $0.9[0.5-1.5]$ & 0.628 & - & - \\
\hline \multicolumn{7}{|c|}{ Children number in house } \\
\hline 1 child & $27(19.0)$ & $115(81.0)$ & 1.0 & & & \\
\hline 2 children & $23(25.0)$ & $69(75.0)$ & $1.4[0.8-2.7]$ & 0.276 & $1.6[0.8-3.3]$ & 0.184 \\
\hline$\geq 3$ children & $24(35.8)$ & $43(64.2)$ & $2.4[1.2-4.6]$ & 0.009 & $2.1[1.1-4.2]$ & 0.043 \\
\hline \multicolumn{7}{|c|}{ Education of care giver } \\
\hline Informal & $3(8.8)$ & $31(91.2)$ & 1.0 & & & \\
\hline Formal & $71(26.6)$ & $196(73.4)$ & $3.7[1.1-12.6]$ & 0.033 & $1.3[0.8-2.2]$ & 0.314 \\
\hline \multicolumn{7}{|l|}{ Malnutrition } \\
\hline No & $44(23.4)$ & $144(76.6)$ & 1.0 & & & \\
\hline Yes & $30(26.6)$ & $83(73.4)$ & $1.2[0.7-2.0]$ & 0.540 & - & - \\
\hline \multicolumn{7}{|c|}{ Neighbour child with diarrhea } \\
\hline No & $54(23.3)$ & $178(76.7)$ & 1.0 & & & \\
\hline Yes & $20(29.0)$ & $49(71.0)$ & $1.3[0.7-2.5]$ & 0.335 & - & - \\
\hline \multicolumn{7}{|l|}{ Fever } \\
\hline No & $53(27.2)$ & $142(72.8)$ & 1.0 & & & \\
\hline Yes & $21(19.8)$ & $85(80.2)$ & $0.7[0.4-1.2]$ & 0.158 & - & - \\
\hline
\end{tabular}


Table 4. Distribution of hospital stay of 301 children with and without Rotavirus infection.

\begin{tabular}{cccc}
\hline Rotavirus infection & Number & Median hospital stay [IQR] & p-value \\
\hline Positive & 74 & $3[2-4]$ days & 0.0297 \\
Negative & 227 & $3[3-5]$ days & \\
\hline
\end{tabular}

Table 5. Hospital stay of vaccinated children with and without Rotavirus infection admitted for acute diarrhea during pre and post-vaccine era.

\begin{tabular}{cccc}
\hline \multirow{2}{*}{ Vaccine era } & \multicolumn{2}{c}{ Median Hospital stay [IQR] } & \multirow{2}{*}{ Author, year } \\
\cline { 2 - 3 } & Rotavirus positive & Rotavirus negative & \\
\hline Pre-vaccine & 3.7 days & 2.5 days & Temu et al., 2011 \\
Pre-vaccine & $4[3-6]$ days & $3[2-4]$ days & Hokororo et al., 2014 \\
Post-vaccine & $3[2-4]$ days & $3[3-5]$ days & Present study, 2018 \\
\hline
\end{tabular}

${ }^{*}$ Mean.

\section{Discussion}

This study has observed the prevalence of rotavirus infection of $24.6 \%$ which is significantly low compared to $49.4 \%$ which was observed in the same setting in pre-vaccinated era [7]. Similar findings have been realized in a recent country wide surveillance in Tanzania, in which a decline of Rotavirus infection among children below five years of age was observed. In this recent study, the decline was from $50.7 \%$ to $17.5 \%$ in Mwanza, whereas in Tanga it was from $39.2 \%$ to $15.9 \%$. The findings on the reduction of this current surveillance are high in comparison from the prevalence obtained in our study compared to that done by Hokororo et al. in pre-vaccine era. This could be attributed to the differences in vaccine coverage in these regions [8]. However, a previous study by Temu et al. conducted in Mwanza, Tanzania among unvaccinated children in pre-vaccine years found the prevalence of Rotavirus infection of $20.7 \%$ [6], which is slightly low compared to the current study. This finding could possibly be due to the fact Temu et al. study used latex agglutination test to detect Rotavirus infection which has low sensitivity and specificity compared to EIA that used in this study. This study has confirmed that successfully Rotavirus vaccination can significantly reduce the prevalence of Rotavirus infection in children.

Before the introduction of Rotavirus vaccine, Rotavirus infection was more common during rainy season. Hokororo et al. study and a Country-wide surveillance in Tanzania, showed that in many settings Rotavirus hospitalizations before vaccine peaked during rainy season (April-July) [7] [8]. Surprisingly, this study has demonstrated that Rotavirus infection was significantly more common during dry season (July, August and September) than during the rainy season (October, November, January and February). This could be explained by the fact that during dry season there is scarcity of water supply which reduces domestic 
hygiene. Similar findings on the seasonality in post-vaccine era were observed in a Country-wide surveillance in Tanzania, whereby Rotavirus infection peaked during dry season (August-September) [8]. This finding is similar to the studies done in South Asia and Northern Venezuela, in which Rotavirus infection was more common during dry season [11] [12]. These findings suggest that there is seasonal variation following the implementation of rotavirus vaccine [8].

This study showed that vomiting was significantly associated with Rotavirus infection, which is similar to the previous studies done in pre-vaccine era in rural Western Kenya, Northwestern Angola, Accra, Ghana, urban Bangladesh and Sudan [13] [14] [15] [16] [17]. This finding is attributed by the fact the virus releases enterotoxin non-structural protein-4 (NSP4) which induces the release of serotonin from human Enterochromaffin cells in the small intestines and activates serotonin receptors on the vagal abdominal afferent and hence induces activation of the nucleus tractus solitarii and area of postrema in the brain stem, which ultimately induces vomiting reflex, nausea and vomiting [18].

This study has found that vaccinated children indwelling with three or more fellow children in the same house are significantly more likely to acquire Rotavirus infection compared to those indwelling with less than three fellow children. This finding is similar to the study done in Chiapas, Mexico in which children indwelling in a house with seven or more people were significantly more likely to acquire Rotavirus infection [19]. This is attributed by the fact that the mode of spread of Rotavirus infection is largely person-to-person transmission, hence as the number of children increases in the house likewise transmission rate increases.

Studies by Temu et al. and Hokororo et al. which were done in Mwanza, Tanzania during pre-vaccine period showed that children with Rotavirus infection stayed longer in the hospital than those without Rotavirus infection [6] [7]. However, in this study, it was found that children with Rotavirus infection had a shorter hospital stay compared to those without Rotavirus infection. This observation is similar to the study done in Accra, Ghana in which children without Rotavirus stayed longer in the hospital than those with Rotavirus infection [15]. This could be explained by the fact that Rotavirus vaccination reduces the severity of diarrhea and hence children recover quickly and ultimately the length of hospital stay is shortened. This confirms that Rotavirus vaccine has reversed the trend of hospitalization.

One of the major limitations of this study is that the study was not done for entire year so the interpretation for Rotavirus seasonality is somehow limited.

\section{Conclusion}

Rotavirus vaccine has significantly reduced the prevalence of Rotavirus infection among vaccinated children with acute diarrhea in Mwanza, Tanzania. In addition, vaccination has reversed the trend of hospitalization among children infected with Rotavirus infection. It is recommended, that the coverage of Rotavirus vaccine should be maintained and emphasized and further studies to deter- 
mine circulating genotypes of Rotavirus and other viruses causing diarrhea during this vaccination era are warranted in developing countries where rotavirus vaccination is implemented.

\section{Ethical Approval}

The ethical approval to conduct the study was sought from the joint Catholic University of Health and Allied Sciences/Bugando Medical Centre Research and Ethics Review Committee with ethical clearance number CREC/208/2017. Parental/guardian consent was obtained for each child prior recruitment.

\section{Availability of Data and Materials}

All data have been included in this manuscript.

\section{Funding}

The research was funded by the University of Dodoma, Tanzania and World Health Organization (WHO). Funders had no role in execution of this study.

\section{Author Contributions}

Conceived and designed the study: DM, AH, SEM and MMM. Data collection and laboratory testing: DM, FM, DRM, ECB, ENK, AH, SEM and MMM. Analyzed the data: DM, AH, SEM and BRK. Wrote the paper: DM and DRM. Edited and reviewed critically the manuscript: AH, SEM and MMM. All authors read and approved the final manuscript.

\section{Acknowledgements}

The authors would like to acknowledge the technical support provided by the members of the Department of Pediatrics and Child health at Nyamagana District hospital, Sekou-Toure Regional Referral hospital and Bugando Medical Centre as well as the members of the Bugando Hospital Laboratory.

\section{Competing Interest}

The authors declare that there is no competing interest.

\section{References}

[1] Johansson, E., Wardlaw, T., Binkin, N., et al. (2009) Diarrhoea: Why Children Are Still Dying and What Can Be Done. The Lancet, 375, 870-872.

[2] Glass, R.I., Parashar, U.D., Bresee, J.S., et al. (2006) Rotavirus Vaccines: Current Prospects and Future Challenges. The Lancet, 368, 323-332. https://doi.org/10.1016/S0140-6736(06)68815-6

[3] Platts-Mills, J.A., Amour, C., Gratz, J., et al. (2017) Impact of Rotavirus Vaccine Introduction and Post-Introduction Etiology of Diarrhea Requiring Hospital Admission in Haydom, Tanzania, a Rural African Setting. Clinical Infectious Diseases, 65, 1144-1151. https://doi.org/10.1093/cid/cix494

[4] Fischer, T.K., Viboud, C., Parashar, U., et al. (2007) Hospitalizations and Deaths 
from Diarrhea and Rotavirus among Children < 5 Years of Age in the United States, 1993-2003. Journal of Infectious Diseases, 195, 1117-1125.

https://doi.org/10.1086/512863

[5] WHO UNICEF (2004) Immunization Vaccination and Biologicals. https://www.who.int/immunization/en/

[6] Temu, A., Kamugisha, E., Mwizamholya, D.L., et al. (2011) Prevalence and Factors Associated with Group A Rotavirus Infection among Children with Acute Diarrhea in Mwanza, Tanzania. The Journal of Infection in Developing Countries, 6, 508-515. https://doi.org/10.3855/jidc.1816

[7] Hokororo, A., Kidenya, B.R., Seni, J., et al. (2014) Predominance of Rotavirus G1 [P8] Genotype among Under-Five Children with Gastroenteritis in Mwanza, Tanzania. Journal of Tropical Pediatrics, 60, 393-396.

https://doi.org/10.1093/tropej/fmu028

[8] Jani, B., Hokororo, A., Mchomvu, J., et al. (2018) Detection of Rotavirus before and after Monovalent Rotavirus Vaccine Introduction and Vaccine Effectiveness among Children in Mainland Tanzania. Vaccine, 36, 7149-7156.

[9] Kish, L. (1965) Survey Sampling. Wiley, New York.

[10] WHO (2017) Diarrhoeal Diseases. http://wwwwhoint/mediacentre/factsheets/fs330/en

[11] Jagai, J.S., Sarkar, R., Castronovo, D., et al. (2012) Seasonality of Rotavirus in South Asia: A Meta-Analysis Approach Assessing Associations with Temperature, Precipitation, and Vegetation Index. PLoS ONE, 7, e38168.

https://doi.org/10.1371/journal.pone.0038168

[12] Schael, I.P., González, R. and Salinas, B. (2009) Severity and Age of Rotavirus Diarrhea, But Not Socioeconomic Conditions, Are Associated with Rotavirus Seasonality in Venezuela. Journal of Medical Virology, 81, 562-567.

https://doi.org/10.1002/jmv.21420

[13] Omore, R., Tate, J.E., O’Reilly, C.E., et al. (2016) Epidemiology, Seasonality and Factors Associated with Rotavirus Infection among Children with Moderate-to-Severe Diarrhea in Rural Western Kenya, 2008-2012: The Global Enteric Multicenter Study (GEMS). PLoS ONE, 11, e0160060. https://doi.org/10.1371/journal.pone.0160060

[14] Gasparinho, C., Piedade, J., Mirante, M.C., et al. (2017) Characterization of Rotavirus Infection in Children with Acute Gastroenteritis in Bengo Province, Northwestern Angola, Prior to Vaccine Introduction. PLOS ONE, 12, e0176046. https://doi.org/10.1371/journal.pone.0176046

[15] Enweronu-Laryea, C.C., Sagoe, K.W., Glover-Addy, H., et al. (2011) Prevalence of Severe Acute Rotavirus Gastroenteritis and Intussusceptions in Ghanaian Children under 5 Years of Age. The Journal of Infection in Developing Countries, 6, 148-155. https://doi.org/10.3855/jidc.1667

[16] Verkerke, H., Sobuz, S., Ma, J.Z., et al. (2016) Malnutrition Is Associated with Protection from Rotavirus Diarrhea: Evidence from a Longitudinal Birth Cohort Study in Bangladesh. Journal of Clinical Microbiology, 54, 2568-2574. https://doi.org/10.1128/JCM.00916-16

[17] Magzoub, M.A., Bilal, N.E., Bilal, J.A., et al. (2014) Rotavirus Infection among Sudanese Children Younger than 5 Years of Age: A Cross Sectional Hospital-Based Study. Pan African Medical Journal, 16, 88 https://doi.org/10.11604/pamj.2013.16.88.2519

[18] Hagbom, M. (2015) Rotavirus Disease Mechanisms Diarrhea, Vomiting and In- 
flammation: How and Why. Linköping University Electronic Press, Linköping. https://doi.org/10.3384/diss.diva-117895

[19] Sánchez-Uribe, E., Esparza-Aguilar, M., Gastañaduy, P.A., et al. (2013) Risk Factors Associated with Rotavirus Gastroenteritis during a Community Outbreak in Chiapas, Mexico during the Postvaccination Era. Journal of the Pediatric Infectious Diseases Society, 2, 15-20. https://doi.org/10.1093/jpids/pis077

\section{List of Abbreviations}

BMC: Bugando Medical Centre

ELISA: Enzyme Linked Immune-Sorbent Assay

CUHAS: Catholic University of Health and Allied Sciences

CI: Confidence Interval

IQR: Interquartile Range

IVDP: Immunization and Vaccination Development Programme

OR: Odds Ratio

WHO: The World Health Organization 